\title{
PEDAGOGIA ECO-ANCESTRAL: CAMINHOS PARA (R)EXISTÊNCIA DE INFÂNCIAS NEGRAS
}

\author{
Joelma dos Santos Rocha Trancoso \\ Instituto Federal do Espírito Santo - IFES \\ Kiusam Regina de Oliveira \\ Universidade de São Paulo (USP)
}

\begin{abstract}
RESUMO
O presente artigo busca discorrer e problematizar o percurso histórico e legal da educação infantil, primeira etapa da educação, a partir da exclusão da negritude no processo histórico e pedagógico, o qual invisibiliza a cultura e epistemologia negra. Apresenta os esforços do movimento de mulheres e do movimento negro para a garantia ao direito à educação. Por meio de revisão bibliográfica aponta os documentos oficiais legais que ratificam o ensino de história e cultura africana e afro-brasileira na educação infantil, como também propõe o rompimento das práticas que silenciam e marginalizam corpos negros, apresentando o caminho da Pedagogia Eco-Ancestral (Oliveira,2019) enquanto possibilidade teórica, prática e metodológica de modificar paradigmas estruturais que reproduzem o racismo entre os profissionais da Educação. Por fim, a partir da Pedagogia Eco-Ancestral, ratificamos a importância de se problematizar os métodos e materiais utilizados nas unidades de ensino, compreendendo as experiências e relações que se afirmam nas instituições de educação infantil com as crianças a partir da mediação dos professores, problematizando suas realidades e suas histórias, no esforço crítico e conscientemente voltado a garantir uma educação antirracista, evitando, assim, consequências danosas para as crianças e adultos negros, como também para toda sociedade.
\end{abstract}

Palavras-chaves: Educação Infantil; Educação Antirracista; Pedagogia Eco-Ancestral;

\begin{abstract}
This article seeks to discuss and problematize the historical and legal trajectory of early childhood education, the first stage of education, from the exclusion of blackness in the historical and pedagogical process, which makes black culture and epistemology invisible. It presents the efforts of the women's movement and the black movement to guarantee the right to education. Through a bibliographic review, he points out the official legal documents that ratify the teaching of African and Afro-Brazilian history and culture in early childhood education, as well as proposing the breaking of practices that silence and marginalize black bodies, presenting the path of Eco-Ancestral Pedagogy (Oliveira, 2019) as a theoretical, practical and methodological possibility of modifying structural paradigms that reproduce
\end{abstract}


racism among Education professionals. Finally, based on Eco-Ancestral Pedagogy, we ratify the importance of problematizing the methods and materials used in teaching units, understanding the experiences and relationships that are affirmed in early childhood education institutions with children through the mediation of teachers, problematizing their realities and their stories, in a critical effort and consciously aimed at guaranteeing an anti-racist education, thus avoiding harmful consequences for black children and adults, as well as for the whole society.

Keywords: Early Childhood Education; Anti-racist Education; Eco-Ancestral Pedagogy. 


\section{Questões reflexivas introdutórias}

[...] TAYÓ projeta em seu penteado, mesmo sem se dar conta disso, todas as memórias do sequestro dos africanos e das africanas, sua vinda à força para 0 Brasil nos navios negreiros, os grilhões e correntes que aprisionavam seus corpos $^{1}$.

Tayó é uma personagem, menina e criança negra, criada pela escritora Kiusam de Oliveira e narrada no livro de prestígio internacional chamado: “O Mundo no Black Power de Tayó”, da Editora Peirópolis, 2013, ilustrado por Taísa Borges. A autora a apresenta como uma menina cheia de orgulho e autoestima, que na sua infância enfrenta e responde com muita propriedade posturas e comentários racistas. Tayó é uma criança empoderada e consciente de sua negritude, como toda criança deveria ser, pois encontra na mãe, referenciais que fortalecem a sua identidade de criança negra. Paulo Freire (2005, p. 11) afirma que "a leitura do mundo antecede a leitura da palavra". Infelizmente, muitas de nossas crianças negras ainda sofrem com os resquícios de um país fundamentado pelos ideais do colonialismo, pois vivem as consequências disso na própria pele. A Educação Infantil, desde sua concepção, também reproduz certas marcas e processos de exclusão capazes de fomentar a negação de corpos negros.

Segundo a Lei de Diretrizes e Bases da Educação Nacional - LDB 9394/96 -, a Educação Infantil caracteriza-se como primeira etapa da Educação Básica, direito da criança, dever do estado e da família, com obrigatoriedade de matrícula para idades de 4 a 5 anos, e opção de matrícula para crianças de até 3 anos de idade.

A LDB desempenhou o importante papel de universalização e obrigatoriedade ao acesso para todas as crianças a partir de 1996, minimizando a exclusão, referente a matrícula, da criança negra ao direito à educação infantil no Brasil. No entanto, há de se considerar que o direito adquirido pela referida lei faz referência ao longo e denso processo histórico de marginalização das crianças, principalmente negras, nas

\footnotetext{
${ }^{1}$ Fragmento do livro "O mundo no black power de Tayó" em Oliveira (2013, p. 28).
} 
instituições escolares. Essas percepções foram demarcadas na trajetória legal da Educação Infantil, e por consequência, nas ações pedagógicas de cunho hegemônico. Deste modo, para além da garantia da oferta e ampliação de vagas, faz-se necessário compreender a especificidade desta etapa da educação básica e se pensar a sua construção, levando em consideração o contexto sociocultural dos sujeitos, sua trajetória, suas singularidades, tanto em âmbito municipal quanto estadual e federal.

Por compreender essa complexidade, Oliveira (2020) afirma:

Tendo em vista a arapuca social que o adulto também um dia já encontrou montada para ele, e com a qual muitas vezes se conformou, penso que ele tem a oferecer uma educação pautada na barbárie. De acordo com alguns dicionários, barbárie é a condição daquilo que é selvagem, cruel, desumano e grosseiro, ou seja, quem ou o que é tido como bárbaro. Ela pode também ser interpretada como uma ação em que a violência é atroz, usada com o único objetivo de afetar diretamente a paz e a tranquilidade de determinado grupo, desrespeitando, inclusive, as leis (p. 4-5).

A relação de barbárie e educação definidos por Oliveira (2020) são facilmente revividos na educação infantil. Cavalleiro (2000) relata, a partir de sua pesquisa, que durante essa fase

Crianças brancas revelaram um sentimento de superioridade, assumindo em diversas situações atitudes preconceituosas e discriminatórias, xingando e ofendendo as crianças negras, atribuindo caráter negativo à cor da pele", ao passo que as "crianças negras já apresentam uma identidade negativa em relação ao grupo étnico ao qual pertencem (p. 118).

Não trabalhar essas questões no espaço escolar resulta em consequências danosas para as crianças e adultos negros, como também para toda sociedade, afinal, é no espaço escolar

(...) que as crianças negras aprendem suas primeiras lições sobre o racismo seja por parte dos profissionais diversos envolvidos no espaço escolar ou seja por parte das próprias crianças não negras que são capazes de reproduzir práticas racistas que 
aprendem em seus espaços de convivência, quase que livremente (OLIVEIRA, 2020, no prelo) $)^{2}$.

Oliveira (2020) ainda reforça que isso só ocorre por conta dos aprendizados, a partir da barbárie, que as crianças vivenciam desde a mais tenra idade, num país que se estrutura, diuturnamente, no açoite dos corpos, das corporeidades e dos ideais altruístas que qualquer pessoa negra possa ter, açoite esse consentido e normalizado na e pela sociedade brasileira, fruto do racismo estrutural. "O racismo estruturado em nossa sociedade pode ser visto como o caos que tem desestruturado a possibilidade real e concreta de crianças negras construírem identidades saudáveis e positivas" (idem, ibidem, no prelo).

Para Cavalleiro (2000), a carência de trabalhos voltados para questão étnico-racial no projeto político pedagógico (PPP), no currículo e consequentemente nas práticas diárias do cotidiano escolar, contribuem para o fomento e manutenção do racismo presente na sociedade e também na escola. A autora ressalta que o silêncio não significa ausência de conflitos.

\section{Marcadores da Pedagogia Eco-Ancestral}

[...] Vamos para o quintal caminhar entre as flores e plantas. Elas, guardiãs das seivas que curam, precisam testemunhar o que estamos vivendo para conseguirem te curar3.

Em contrapartida a esse silenciamento, Oliveira (2019) nos apresenta caminhos, ação e reflexão para superar a barbárie imposta às infâncias negras. A base teóricometodológica e prática concebida como Pedagogia Eco-Ancestral, que:

[...] estabelece uma ruptura provocada pela decolonialidade: não se trata mais de falar pelo corpo, mas proporcionar situações para que o próprio corpo fale por si, alimentado pela cultura vivida na e pela carne. Esse corpo-templo que se (re)significa na e para a resistência, com o propósito de se tornar um corpo-

2 Esse texto sairá em uma publicação do SESC-SP m novembro/2020.

3 Fragmento do livro O Black Power de Akin, de Kiusam de Oliveira, Editora de Cultura, ilustrações de Rodrigo Andrade. 
templo-resistência - porque resistir às atrocidades também é sagrado -, acaba por estar conectado com a realidade vivida na coletividade, em seu entorno e, dessa forma, é um corpo capaz de sobreviver às intempéries sociais (OLIVEIRA, 2019, p. 2).

A Pedagogia Eco-Ancestral promove o reestabelecimento de laços de reconhecimento, valorização e empoderamento de quem entra em contato com ela, mergulho e enfrentamentos das emoções mais profundas presentes em cada ser: tudo isso a partir do acesso a afro-ancestralidade, o encontro com a cosmovisão africana, ou como preferimos dizer/sentir, com nossa cosmopercepção africana e afro-brasileira, pois:

[...] considera os conhecimentos ancestrais como elementos-chave para qualquer tipo de aprendizagem, que podem ser encontrados em plataformas diversas, como histórias de vida, memórias, provérbios, mitos, itans, letras de músicas, literaturas, danças, gestualidades, poemas, performances etc., e tem no corpo-templo um território sagrado, consciente de que precisa ser reestruturado como um corpo-templo-resistência que seja capaz de combater o racismo institucional e a necropolítica cotidianos, em uma perspectiva sóciocosmo-política (OLIVEIRA, 2019, p. 17).

Dessa forma, a Pedagogia Eco-Ancestral concebe no trato pedagógico que a presença da cultura afro-brasileira deve fazer parte da Educação Infantil, tanto no currículo, como na constituição de sua própria identidade enquanto unidade de ensino, atravessando métodos, conteúdos, espaços, práticas pedagógicas e brincadeiras, como determina a LDB (9394/96).

Entendendo que formação e manutenção de um corpo-templo-resistência de infâncias negras não devem ser compreendidas apenas pela valorização da estética negra, mas sim, articuladas junto da questão da herança/legado das culturas africana e afro-brasileira, compreendendo fundamentalmente, os valores civilizatórios afrobrasileiros como: "Circularidade, Religiosidade, Corporeidade, Musicalidade, Memória, Ancestralidade, Cooperativismo, Oralidade, Energia Vital e Ludicidade" (A Cor da Cultura, 2010). Aqui, as brincadeiras na educação (ludicidade), nas aprendizagens são fundamentais.

Nesse sentido a Pedagogia Eco-Ancestral, fundamentada pelos saberes da diáspora africana, compreende na totalidade das experiências, possibilidades de aprender e 
entender saberes ancestrais, quanto aos modos de criar, pertencer a um todo, portanto, de ser e (r) existir aqui, na coletividade.

Para Oliveira (2019, p.2) a ancestralidade é “[...] um posicionamento político contrário ao que se estabeleceu no país como uma lógica incontestável, direcionada ao branco, considerado a norma, enquanto o não-branco é o desvio”. Deste modo, a Pedagogia Eco-Ancestral que se constitui enquanto forma de resistência contra as barbáries provocadas pelas práticas pessoais (nunca neutras), e se utiliza da Ancestralidade para ir ao encontro da quebra de paradigmas colonizadores que desumanizam nossas infâncias negras, busca atuar no território do próprio inimigo a branquitude e o racismo -, a partir do caos instaurado por ele próprio. É uma pedagogia que resiste à hegemonia epistemológica eurocentrada e ao epistemicídio.

Assim, o que é o caos? Sem maiores detalhes, vale dizer que no caos cabe a ideia de que uma mudança pequena no início de qualquer ação "pode provocar consequências gigantescas e desconhecidas, o caos. Tal mudança pode ser algo imprevisível” (Oliveira, 2020, no prelo).

Oliveira (2019) apresenta 10 princípios básicos da Pedagogia Eco-Ancestral, a saber:

1) É uma pedagogia feminina e combate o sexismo; 2) As infâncias são territórios de ação dos Direitos Humanos; 3) Há consciência de que existe a colonialidade no e do poder; 4) Estabelece ruptura a partir da decolonialidade; 5) Necessidade de emancipação epistêmica; 6) Importância da formação para a Educação das Relações Étnico-Raciais; 7) Luta por uma educação antirracista; 8) Tudo se dá na relação profunda com a ecossistema; 9) Necessidade da ressignificação do conceito de corpo para o corpo-templo-resistência; 10) Tudo deve se dar de forma a considerar a Ancestralidade.

1. É uma pedagogia feminina e combate o sexismo: um dos mitos iorubanos narra Oduduwá como feminina e criadora/provedora do plante Terra. Há inúmeros mitos espalhados pelo mundo que afirma o protagonismo feminino e é atrás deles que profissionais da educação devem também, apoiar seus repertórios; 
2. As infâncias são territórios de ação dos Direitos Humanos: destacar como base para a fundamentação em documentos focados nos Direitos Humanos, como a Constituição Federal, o Estatuto da Criança e do Adolescente (ECA), o Estatuto da Igualdade Racial, a Lei de Diretrizes e Bases (LDB 9394/1996) que rege a Educação Brasileira, as leis 10.639/o3 e 11.645/o8 que alteraram a LDB em seus artigos 26, 26A e 79B, a Lei Caó, a Organização das Nações Unidas (ONU) - Década Internacional de Afrodescendentes (20152024);

3. Há consciência de que existe a colonialidade no e do poder: reconhecer que o projeto imperial, tal como afirma Achille Mbembe (2018, p. 118) "que a espinha dorsal do projeto imperial era a diferença racial”. A realidade de que ele retrata é fora do nosso país, contudo, não nos esqueçamos que o capítulo do Brasil Colônia é caracterizado pelo intenso tráfico de pessoas negras africanas para serem usadas como mão-de-obra gratuita para o desenvolvimento do país; essa consciência permite compreender os processos de exclusão e desumanização dos sujeitos negros;

4. Estabelece ruptura a partir da decolonialidade: consciente do que e de como se deu a violação dos corpos e experiências negras em liberdade pelos senhores de engenho é fundamental trazer esse universo à tona, romper com a postura de aceitação de como tudo se deu (e ainda se dá) com relação à desvalorização do ser negro, buscando formas para romper com isso;

5. Necessidade de emancipação epistêmica: as universidades brasileiras desconsideram, secularmente, nos currículos (ou nas práticas) dos cursos e disciplinas o corpo de intelectuais negros, sendo necessário que tal continuidade seja rompida e questionada; na medida que descolonizamos nossos pensamentos/conhecimentos também descolonizaremos nossos corpos;

6. Importância da formação para a Educação das Relações ÉtnicoRaciais: formação continuada aos profissionais da educação intensa e constante, incluindo formações nas epistemologias negras como forma de ampliar mergulho nas lutas antirracistas; 
7. Luta por uma educação antirracista: como afirmou Angela Davis "Numa sociedade racista não basta não ser racista. É necessário ser antirracista” e isso requer práticas antirracistas em ação, afinal, compreende o importante papel da educação para formar cidadãos comprometidos uns com os outros e com o mundo (social e ecológico/biológico);

8. Tudo se dá na relação profunda com a ecossistema: somos seres ecológicos e tudo na educação precisa se dar de forma transversal, incluindo a relação entre seres humanos aos seres vivos em geral presentes na natureza; uma sociedade biótica com fatores bióticos, isto é, os efeitos causados pelos organismos em um ecossistema, que condicionam as populações que o formam e o corona vírus faz parte de tudo isso que está sendo pincelado aqui;

9. Necessidade da ressignificação do conceito de corpo para o corpotemplo-resistência: aqui, vale a ideia de que as crianças negras chegam nas escolas brasileiras, espações onde descobrem o racismo, despreparadas e é fundamental que nós, adultos, cheguemos antes com nossos ensinamentos e fortalecimento intenso das identidades negras infantis a partir do próprio corpo que precisa ser "treinado" dentro dos valores preciosos ao empoderamento negro que, para sobreviver, necessita, construir um contra-corpo afrodescendente (OLIVEIRA, 1998) que visa transformá-lo, através de muito amor e consciência racial, num corpo-templo-resistência, entendendo o corpo como sagrado e que por isso, combater as práticas ligadas à barbárie se faz também, sagrado.

10. Tudo deve se dar de forma a considerar a Ancestralidade Africana: aqui, valores fundamentais a serem trabalhados são, para além da própria Ancestralidade, a Oralidade, a Circularidade, o Comunitarismo e a Ludicidade nos conhecimentos de forma circular e espiralada ascendente

Tais princípios da Pedagogia Eco-Ancestral formam uma unidade teórica, prática e metodológica que abraça a consciência do ser, e do me fazer (ser), para compor com os tantos outros no movimento de luta e resistência contra o racismo. 


\section{A Pedagogia Eco-Ancestral e o Acolhimento das Infâncias Negras}

[...] não é preciso ser adulto para ser sábio. A sapiência surge por meio das vivências, da generosidade de quem ensina, da humildade de quem aprende, não importa a idade 4 .

Ao refletir sobre as infâncias, Oliveira (2020) chega ao conceito de arapuca social capaz de capturar o bebê, assim que nasce, a partir dos familiares ligados diretamente a eles. Ela fala que tal captura se dá assim que o bebê sai da útera, sempre materna (por isso o feminino no substantivo), e encontra um universo povoado de cores rosa ou azul, dependendo de seu sexo: meninas-rosa, meninos-azul. E a captura continua nos brinquedos oferecidos às crianças: bonecas-meninas, carrinhos-menino. Desconsidera-se, portanto, a expertise que um bebê tem em termos de protagonismos e autonomias, afinal, Oliveira (2020) lembra que que o bebê aprende dentro da barriga da mãe, a respirar, nadar, sorrir, se consolar, se alimentar e mudar de posição, sozinho. Com o passar dos anos, esse bebê vai crescendo e se deparando com regras sexistas do tipo "menino pode" e "menina não pode", além das meninas serem ensinadas, inclusive pelas próprias mães a se silenciarem quando "o papai está falando" ou como é importante uma menina ser prendada, aprender a fazer tudo no lar para que possa arranjar um "bom homem para se casar" e certamente "ter filhos lindinhos, branquinhos como anjos e educados”. Quer mais barbárie do que essas citadas? Poderia aqui trazer uma lista considerável de barbáries afirmadas por adultos às crianças, com a certeza de que estão sendo educativos e contribuindo para a educação de seus filhos. Nesse sentido, a autora pergunta "Que tipo de educação o adulto tem para oferecer à criança do século XXI”?

A Pedagogia Eco-Ancestral “[...] enxerga na infância um período primordial para combater posturas que reproduzem aprendizagens discriminatórias e racistas desde as brincadeiras infantis, altamente racializadas pelas crianças" (OLIVEIRA, 2019, p. 2). Além disso, convida profissionais da educação a conhecerem outras culturas e suas filosofias a fim de que ampliem seus universos de informações. Nesse sentido, ao

\footnotetext{
${ }^{4}$ Fragmento do livro O mar que banha a llha de Goré, de Kiusam de Oliveira, São Paulo, Editora Peirópolis, 2014.
} 
destacar como as crianças vivem e estabelecem relações com as infâncias no candomblé, por exemplo, informa:

\begin{abstract}
As crianças no candomblé vivenciam, portanto, a infância não somente nos corpos infantis, pois desde cedo compreendem que "a infância" pode estar presente também em corpos não infantis, de idosas/os, tendo, assim, a possibilidade de compreender que os corpos são perecíveis e fenecem, mas a infância não: ela é um traço da personalidade que pode e deve ser cultivado a vida inteira, a fim de manter-se como chama ativa na continuidade do legado ancestral (Oliveira, 2019).
\end{abstract}

Há muita potência em compreender a infância como um continuum espaçoatemporal, por atingir conhecimentos através de mitos vindos de tempos imemoriais, possível de ser vivida/sentida mesmo por idosos de 90 anos, infâncias vistas como traços da personalidade de uma pessoa.

As crianças, em suas infâncias, deveriam estar preocupadas em construir suas hipóteses para tudo o que há ao redor dela e não lidar com assuntos associados à barbárie, como o racismo.

Para uma criança negra lidar com recusas no brincar ou no empréstimo de lápis de cor por parte das crianças que justificam tais posturas pelo fato da outra criança ser negra é algo violento, pertencente à barbárie. Mas não só: de acordo com Oliveira (2020) a barbárie também se encontra quando num país de maioria negra, gestores públicos não levam isso em consideração nas formações dos profissionais da educação, na compra de livros para a formação de um acervo antirracista, na elaboração do Projeto Político Pedagógico de uma escola, na elaboração do plano gestor de um estado, município ou país, quando você não permite que uma criança negra seja a noivinha na quadrilha ou que represente em papeis teatrais personagens como Branca de Neve, Chapeuzinho Vermelho ou o Pequeno Príncipe: tais posturas marcam profundamente a vidas das crianças negras que rapidamente, poderão ter a autoestima rebaixada pela forma com que o racismo afeta-destrói a vida de crianças negras.

Nesse sentido, como forma de reconstrução identitária, autovalorização e resgate da autoestima que a Pedagogia Eco-Ancestral deve colocar tudo em seus devidos lugares, afinal de contas colocar o continente africano como o Berço da Humanidade é, 
sem sombra para dúvidas crer nos documentos científicos que apontam para isso e a partir deles, reconstruir a rota da educação brasileira, a começar por reafirmar Egito, parte do continente africano e observar, nas Feiras de Ciências, que não há mais espaço para representar em maquetes o Egito com bonequinhos de plásticos rosados, afinal, é fundamental que se revele, afirme e comprove, por exemplo, a negritude da Rainha Cleópatra (69 a. C. a 30 a. C), mulher que encantou e influenciou os imperadores romanos Júlio César, Marco Antônio e Otávio Augusto. Tais conteúdos provocariam um deslocamento epistemológico fundamental para o resgate da autoestima de crianças negras e para a humanização das crianças não negras. Por experiências próprias estamos certas de que tal posicionamento é capaz de transformar vidas das crianças negras, afinal é a possibilidade de cura a partir de aprendizagens significativas para o fortalecimento das identidades negras e não negras.

O acolhimento feito pela Pedagogia Eco-Ancestral das infâncias se dá, inclusive pelos textos literários antirracistas como possíveis potências para reencantar os corpos negros infantis. Tais textos possibilitam um esperançar do olhar infantil sobre a vida e se dão dentro do que Oliveira (2020) tem chamado de Literatura Negro-Brasileira do Encantamento Infantil e Juvenil (LINEBEIJU).

É uma categoria literária focada nos públicos infantil e juvenil, que traz em seu bojo um posicionamento político que se opõe, explicitamente, à hegemonia da episteme e/ou da epistemologia eurocentrada, ao colonialismo e à colonialidade. [...] possui conteúdo antirracista e decolonial, estruturado e conscientemente elaborado para fortalecer as identidades de crianças e jovens negros [...] essencialmente feminina, não por ser escrita somente por mulheres, mas por focar essencialmente nas relações entre raça e gênero, compreendendo o ser mulher em sociedades machistas (pp. 1819).

A LINEBEIJU tem como bases: Ancestralidade, Afrocentricidade, Encantamento, Mulher Negra e a Pedagogia Eco-Ancestral e está ancorada na máxima dita por Carlos Moore (2014) "Nada é mais importante para uma criança que um conto que a insira no mundo dos humanos, dos animais e das coisas. Essa inserção faz-se por meio do apelo à sua imaginação" (p. 6). 


\section{Questões reflexivas sobre o caminhar}

[...] O rosto de Tayó parece uma moldura de valor, “[...] seus OLHOS são NEGROS, tão negros como as mais escuras e belas noites que do alto miram com ternura qualquer ser vivo. Do fundo desses olhos escuros saem faíscas de um brilho que só as estrelas são capazes de emitir5.

Quantas crianças tem suas infâncias negadas e o brilho dos olhos apagados por conta de práticas pedagógicas/educacionais incapazes de potencializar a beleza e cultura da criança negra? Talvez seja impossível contabilizar em números, mas é possível sentir a dor desse apagamento.

A caminhada e o comprometimento do educador da educação infantil perpassam por esse sentir, refletir e fazer. Neste sentido, é primordial que os profissionais desta etapa da educação tenham sensibilidade para ouvir e aprender com as crianças, pensar e problematizar a construção de suas identidades e a leitura de seus corpos e realidades, a fim de combater veementemente manifestações de comportamentos racistas que fomentem o apagamento do brilho dos olhos das crianças negras.

Tal sensibilidade se traduz no combate ao silenciamento e invisibilidade da população negra nas práticas pedagógicas em diversos aspectos, se materializando por meio da prática/reflexão da Pedagogia Eco-Ancestral, repensando os materiais utilizados nas unidades de ensino, compreendendo as experiências e relações que se afirmam nas instituições de educação infantil com as crianças a partir da mediação dos professores, problematizando suas realidades e suas histórias e nos esforçando crítico e conscientemente para garantir uma educação antirracista.

É provável que já se tenha ouvido falar da conhecida frase de Nelson Mandela (1995, p. 115): "Ninguém nasce odiando outra pessoa pela cor de sua pele ou por sua origem, ou sua religião. Para odiar, as pessoas precisam aprender. E se podem aprender a odiar, podem ser ensinadas a amar [...]”.

De tal modo, pensamos que criança nenhuma nasce racista, mas aprende a ser. Por isso, é demasiada a importância de uma concepção teórico, prática e metodológica a exemplo da pedagogia Eco-Ancestral que vá ao encontro da educação das relações

\footnotetext{
5 Fragmento retirado do livro O Mundo no Black Power de Tayó, de Kiusam de Oliveira, ilustrações Taísa Borges, Editora Peirópolis, 2013, p. 8-11, grifos do original.
} 
étnico-raciais logo na primeira infância, para que essas crianças se reconhecerem enquanto sujeitos, independentemente da cor, raça ou religião. É preciso que as instituições de educação infantil promovam o aprendizado de respeitar e conviver com o outro permeados pela condição de alteridade, para assim conviverem em uma sociedade multifacetada e plural, possibilitando a contemplação das belezas e riqueza do patrimônio histórico cultural da humanidade, a partir das contribuições da cultura negra e indígena, por mais crianças empoderamos como a pequena Tayó.

A Pedagogia Eco-Ancestral pode ser o caminho de uma (re)existência positiva para as infâncias negras.

\section{Referencias}

BRASIL. Ministério da Educação e do Desporto. Lei de Diretrizes e Bases da Educação Nacional, 1996.

. Ministério da Educação. Secretaria de Educação Básica. Diretrizes Curriculares Nacionais para a Educação Infantil. Brasília: MEC, SEB, 2010. . Lei $\mathrm{n}^{\mathrm{o}}$. 10.639, de 9 de janeiro de 2003. Estabelece as diretrizes e bases da educação nacional, para incluir no currículo oficial da Rede de Ensino a obrigatoriedade da temática História e Cultura Afro-Brasileira e dá outras providências.

. Lei $\mathrm{n}^{0}$ 11.645, de 10 de março de 2008. Altera a Lei no 9.394, de 20 de dezembro de 1996, modificada pela Lei no 10.639, de 9 de janeiro de 2003, que estabelece as diretrizes e bases da educação nacional, para incluir no currículo oficial da rede de ensino a obrigatoriedade da temática "História e Cultura Afro-Brasileira e Indígena.

CAVALLEIRO, Eliane dos Santos. Do silêncio do lar ao silêncio escolar: racismo, preconceito e discriminação na educação infantil. São Paulo: Contexto, 2000. 
. Eliane dos Santos (Org.). Racismo e anti-racismo na Educação repensando nossa Escola. São Paulo: Summus, 2001.

. Eliane dos Santos. Relações raciais no cotidiano escolar: implicações para a subjetividade e a afetividade, p. 82-96. In; BRANDÃO, Ana Paula. Saberes e fazeres: modos de ver. Rio de Janeiro: Fundação Roberto Marinho, 2006. v. 1.

FREIRE, Paulo. A Importância do Ato de Ler em três artigos que se completam. São Paulo: Cortez, $46^{\circ}$ ed., 2005.

GOMES, Nilma Lino. Trajetórias escolares, corpo negro e cabelo crespo: reprodução de estereótipos ou ressignificação cultural? Revista Brasileira de Educação, Rio de Janeiro, n. 21, p. 40-51, Set./Out./Nov./Dez. 2002.

MANDELA, Nelson Rolihlahla. Long Walk to Freedom: The autobiography of Nelson Mandela. New York: Back Bay Books, 1995.

MOORE, Carlos. Prefácio. In.: O mar que banha a Ilha de Goré. Sã Paulo: Editora Peirópolis, 2014.

OLIVEIRA, Kiusam de. Ọmọ-oba Histórias de Princesas. Belo Horizonte: Mazza edições, 2009.

. O mundo no black power de Tayó. São Paulo: Editora Peirópolis, 2013.

- O mar que banha a ilha de Goré, de Kiusam de Oliveira. São Paulo: Editora Peirópolis/Fundação Biblioteca Nacional, 2014.

- O black power de Akin. São Paulo: Editora de Cultura, 2020.

- Oficina com Kiusam de Oliveira redimensiona a noção de corpo a partir da Ancestralidade Africana. Ceará. 2017. Palestra concedida à reportagem da Universidade da Integração Internacional da Lusofonia Afro-Brasileira. Disponível em: <http://unilab.edu.br/noticias/2017/o4/20/oficina-com-kiusam-de-oliveira- 
redimensiona-a-nocao-de-corpo-a-partir-da-ancestralidade-africana/>. Acesso em: 25 ago. 2020.

. Pedagogia da Ancestralidade. SESC, São Paulo, 18 de junho de 2019.

Disponível em: <https://www.sescsp.org.br/online/artigo/compartilhar/13431_PEDAGOGIA+DA+

. O racismo e a arapuca social (parte 1). Blog das Letrinhas, São Paulo, 26 de junho de 2020. Disponível em:

$<$ https://www.blogdaletrinhas.com.br/conteudos/visualizar/O-racismo-e-a-arapucasocial>. Acesso em: 20 de agosto 2020.

. Literatura negro-brasileira do encantamento infantil e juvenil:

reencantando corpos negros. In.: Perspectivas na educação em narrativas, memórias e educação popular: psicopedagogia, racismo e cultura / Maria Eliene Magalhães da Silva (org). - Fortaleza: Imprece, 2020.

\section{Sobre os autores:}

Joelma dos Santos Rocha Trancoso: Graduada em Pedagogia pela Universidade Federal do Espírito Santo - UFES. Mestra em Educação em Ciências e Matemática pelo Instituto Federal do Espírito Santo - IFES. Professora estatutária no município da Serra/ES desde 2013, onde atualmente é gestora da pasta Étnico-racial na Secretaria Municipal de Educação -Sedu/Serra. Tem interesse pelas temáticas relacionadas a Educação das Relações Étnico-raciais- ERER, a Educação de Jovens e Adultos-EJA e a Educação Matemática. E-mail: jhoelmasrocha@gmail.com

Kiusam Regina de Oliveira: Doutora em Educação e Mestre em Psicologia pela Universidade de São Paulo. Pedagoga habilitada em Orientação Educacional, Administração Escolar e Deficiência Intelectual. Escritora. Artista multimídia. Arteeducadora. Bailarina e coreógrafa. Contadora de histórias da mitologia afro-brasileira. Foi orientadora pedagógica do projeto Geração XXI, o primeiro de Ação Afirmativa do país. Foi Chefe de Educação Especial do município de Diadema/SP de 2005 até 2008. Assessorou a implementação da Lei 10.639/03 em Diadema de 2005 a 2016. Em 2010 e 2011, atuou como assessora na Secretaria de Cultura de Diadema nos assuntos da cultura voltados para as questões de gênero e raça, tendo como foco a dança. Em 2013, assessorou a PMSP - DOT-P-Guaianases para a implementação da lei 10.639/o3 na região de São Paulo. Em 2010 foi representar o Brasil na FESMAN (Festival Mundial de Artes Negras), no Senegal. Tem palestrado pelo Brasil sobre a temática das relações 
étnico-raciais, focando em: educação das relações étnico-raciais, infância negra, mulher negra, identidade negra, candomblé e educação, corporeidade afro-brasileira, danças afro-brasileiras e sobre implementação da lei 10.639/o3. Com estes temas tem orientado TCC's, dissertações e teses e participado de bancas examinadoras. E-mail: kiusam.oliveira@gmail.com 